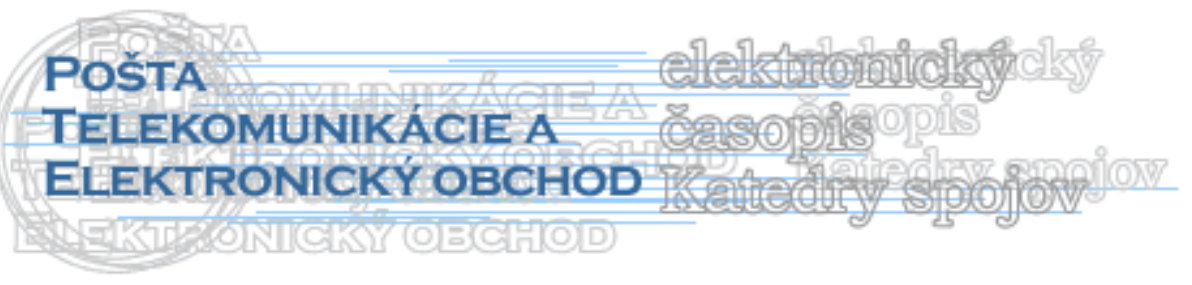

\title{
POSSIBLE AREAS OF APPLICATION OF THE GEOGRAPHIC INFORMATION SYSTEM IN POSTAL TRAFFIC
}

\author{
Biljana Grgurovic, Slavica Strbac1
}

\section{Introduction}

The idea of increasing the volume of postal services, especially those related to personal correspondence, has not been the in the focus of business activities of large postal systems for a long time. The future lies in redirecting the business means and increased use of computer and communication technologies. The factors that have changed the course of development were, in the first place, the occurrence of private courier services for parcel deliveries that have applied different business models, the occurrence and rapid development of e-business, reducing the volume of business correspondence, as well as the change of needs, requirements and standards of quality from the viewpoint of a user. [1] It is necessary to make an adequate use of the traditional advantages of postal organizations such as the possibility of universal delivery, great availability and recognizability [2], by transferring them into a computer surrounding.

It is well known that the geographic information system - GIS implies an organized set of hardware, software, geographic data and users, and that it has been designed to enable efficient collecting, managing, manipulation, analysis, modelling and presentation of data related to a certain spatial area. From different points of view, it could be highly interesting, in a business sense, to companies engaged in traffic, production or service providing, which includes the that the Public Enterprise of PTT Communications "Serbia" that, using the existing infrastructure, may accomplish quantitative, qualitative and financial efficiency, for both the services from the areas of business it was registered for and those business activities that would supplement the range of existing products and services.

In relation to the above mentioned, the paper explains some of the areas where it is possible to adjust postal capacities to new means of business - the area of delivery service organization and parcel transport, finding the shortest way, the part that is engaged in analyzing the locations of postal network units, market segmentation and the cases of solving some other issues where decisions are being made primarily on the basis of spatial data relevant for that issue.

\footnotetext{
1 B. Grgurović, ICT College for Vocational Studies, Postal and Banking Technologies, Z. Čelara 16, 11000 Belgrade, Serbia tel: +381113290828

e-mail: biljana.grgurovic@ict.edu.rs,

Slavica Štrbac, ICT College for Vocational Studies, Postal and Banking Technologies, Z. Čelara 16, 11000

Belgrade, Serbia

tel: +381113290828

e-mail: slavica.strbac@ict.edu.rs
} 


\section{The Aplication of GIS technology in postal traffic}

A large number of events that have occurred as a consequence of functioning of postal traffic have spatial component, which means that it is possible to adjoin coordinates, address and postal code to the information related to them, and, simultaneously, present them on a chart, diagram or table.

\section{GIS as a manager of a transport database}

As a consequence of the need for transportation of large quantities of parcels on a daily basis, postal systems had to grow into large transport organizations as well. Taking into consideration the distances that postal transportation vehicles have to cross daily in order to fulfil their basic tasks, the need for optimal or, at least, rational organization of this kind of work seems quite clear.

For the purpose of obtaining road databases and maps of terrain conditions, it is possible to efficiently use the advantages of GIS. As the result, one obtains routs homogenous by their functional classification and jurisdiction, wit all their physical characteristics.

\section{The implementation of postal address code in GIS}

Postal address code - PAC has appeared as a consequence of the need for solving the issue of fast, quality and less expensive automatic parcel sorting. Realization of this project in the area of the Public Enterprise of PTT Communications "Serbia" started towards the end of 2001, when the regulations for code assignment were set, as well as the principles of connecting with the official codes for municipalities, settlements and streets proposed by the Statistical Office of the Republic of Serbia. Each point of the territory of the Republic of Serbia was defined by twelve code digits.

PAC has obtained its visual shape, i.e. clearly visible area boundaries, through GIS, which has helped it in its further upgrade. [3] In order to make vector map compatible with PAC, it is necessary that every mapped point possess the adequate code. All databases that are being entered into GIS system have to go through the process of matching with postal address code.

Territorial management has also become possible. With further development of the project, PAC, alongside with the geographic information system, has come out of the frame of postal services and became a powerful weapon, operating with spatial and informational data.

\section{The application of GIS in delivery organization}

The liberalization of postal market [4] and circulation of various sorts of parcels determine the development of new means of delivery. Also, the appearance of new services in the area of financial transactions and electronic data transfer, affects the concept of specialized urgent delivery. All the above mentioned, alongside with the reminiscence that classical delivery has already encountered the problem of decreased resources in big cities and over dimensioned capacities in rural delivery, tells us that delivery, as the most complex and most expensive process in distribution of postal parcels, should be seriously taken into consideration. The application of GIS technology under those circumstances is not only possible, but quite advisable as well. As early as the experimental phase, this technology has proved itself capable of coping with all the challenges concerning delivery organization. The seriousness of these issues has made the Serbian Post Office simultaneously work on the 
formation of delivery areas, introducing postal address code as the basic precondition for regular routing and automatic sorting of postal parcels and development of the geographic information system.

Using the option that enables the creation of thematic maps via GIS, one can quickly get the picture of the organization of delivery on the territory of a city or an enterprise. On the basis of the available data, it is possible to enter the locations of all post offices, as well as the positions of all settlements in the Republic of Serbia, divide a city map into delivery areas, delivery region areas and areas that belong to different postal address codes. As the result, an overall insight into the capacity and delivery organization mode for the entire Enterprise is obtained. The created thematic map contains data about the belonging delivery post office for each settlement, as well as data about the number of inhabitants, number of telephone bills, number of pensions to be paid per household, address code for each part of the settlement, distance that a mail carrier crosses per region for rural areas etc. Since settlements are marked with different colours depending on the delivery post office they belong to, on the basis of data obtained via GIS, a delivery manager can easily decide on a possible transfer of a settlement into the delivery area of another delivery post office, all for the purpose of optimization of delivery organization.

Introducing new services and increasing the volume of the existing ones results in introducing specialized delivery, which implies special organization of technological means of transport and staff, for the purpose of more efficient and punctual implementation of business activities. Set of different user requirements concerning delivery deadlines, quantities and ways of handling parcels on one side, and types of settlements, vehicles, number of deliverers, their working hours on the other side, generate the need for software tool that should help delivery managers to solve all the issues successfully.

GIS contains all the data within its geographically positioned databases. On the bases of them and additional software tools, it is possible to optimally organize delivery for the analyzed area.

Whenever there is a possibility of a main stroke, and then, a slight decrease of the volume of parcels, GIS becomes an irreplaceable factor in delivery organization. It is able to create, on a daily basis, a new organizational delivery schedule, which directly leads to saving, i.e. improving the service quality, since there is always an optimal number of vehicles operating. Additional improvement of the Truck \& Trace technology, which would, as the output result, give PAC of every parcel and, thus, connect the data about delivered parcels in the destination post office with vector maps, would give a delivery manager the possibility to make an instant decision on the required number of executors and structure of delivery regions for that day. Developed postal directorates are already using the advantages of GIS. Their delivery organization enables the forming of flexible delivery regions, solely on the basis of quantity and sort of parcels that have arrived at the delivery post office. These directorates permanently employ only the number of officers that is necessary for regular deliveries, and in case of the increase of parcel quantity, they use temporarily engaged staff.

It is required to enter the data about the users that generate larger quantities of parcels on a daily basis into the vector map of the delivery area that is being reorganized. Each base that is in use must have PAC within the address. Depending on the type of service, value is assigned to every parcel from the basis. When databases of large users are entered into vector maps and weight coefficients are assigned for those parcels, $15 \%$ of parcels without data still remain. They consist of letter mail sent by individuals, single parcels sent by legal entities and court letters. After the entering of all disposable databases is completed, the sum of service units for each address code is being determined. Project engineer further conducts the process of joining multiple address codes in one item, i.e. delivery region. 
It usually takes several months to carry out the reorganization of delivery area without the use of GIS. With the aid of GIS, PAC and quality databases, this process is reduced to several hours within a single working day.

The distance a deliverer crosses per delivery region can be measured directly from a vector map, almost unmistakably. Beside that, GIS also enables instant assignments for deliverers, on the basis of available databases, and printing delivery books for all sorts of registered parcels. All these functions can be monitored and conducted by a single delivery manager, for the area up to 20 regions, which represents a great saving when it comes to the number of engaged staff. Thus created surplus of staff in the part of business related to direct delivery of parcels, can be used for improving the quality of delivery in nearby delivery post offices or for improving the quality of specialized delivery.

With this type of organization, the basic novelty is the fact that delivery regions are being formed on a daily basis according to the number and sort of parcels arrived at the destination post office.

\section{The application of GIS in the analysis of postal network units}

GIS has become relevant for the postal traffic the moment management realized the importance of spatial data for making decisions on possible closing or changing of locations of the existing, and opening new post offices, on the locations where the concentration of inhabitants and new enterprises significantly affected the increase of the number of potential users.

According to the Basic plan of postal network [5], basic criteria for location planning are the following: spatial, economic and functional. The first step for applying the spatial criterion, as the most important criterion on the occasion of opening of new postal network units, is to determine territorial borders of so called minute zones, i.e. maximum time intervals necessary for postal service users to reach postal network units. The data from the available databases that can be used for this purpose and, at the same time, adequately presented on a vector map are related to the city street network, positions of residential properties with data about the number of inhabitants, business premises with data about activity code and assigned weight factor, the existing post offices with data about income, volume of services and ownership etc.

Using the method of geocoding, positions of post offices and legal entities are entered in a vector map. That implies connecting coordinates and addresses of objects in a vector map with addresses of post offices and legal entities from database. Every object is connected with the information about the belonging number of inhabitants. On the basis of these layers, the new ones are formed that enable the analysis of the locations of post offices using special tools and techniques.

\section{The application of GIS in traffic accident analysis}

It is possible to mark the points on a road network where accidents most commonly occur, with typical cases and scenarios. That enables planners and project engineers who deal with traffic accident analyses or planning, to have a clear insight and give adequate solutions concerning safety. The system also contains data about the conditions and frequency of accidents, which helps identifying dangerous road sections. The information can be highly significant when planning transport of larger quantities of insured parcels. 


\section{The application of GIS in market segmentation}

A public postal operator is obliged to provide the group of reserved postal services on the entire territory of a country. The state guarantees these services to the postal operator as an exclusive right within the frame of a certain limit concerning weight and price. Nevertheless, competition in the area of universal services becomes more and more obvious on the territories of big city entities. If we focus on commercial services, that contain all postal services except the universal ones, including value added services, it is very easy to see that competition most commonly occurs at the express and courier service market. Those are the types of services whose basic added value is door-to-door transport. They have evolved into a separate industry during the last few decades. They equally include transport of documents, letters, packages and merchant goods.

There is no budget subvention proposed by the state and, therefore, no aspect of financial security in these areas. It is a highly profitable market where everybody has to struggle for his/her own share. But in what way? With the development of GIS, i.e. creating sufficient number of vector maps to which large quantities of important data can be attached, the conditions for using this technology in the area of market segmentation have also been created. [6]

The scale of 1:3000 for urban cores provides recognition of objects. The first thing that should be taken into consideration when using ortho-photo images for creating a vector map is the year of the recording. If it is not that recent, some new buildings or even entire streets could be omitted. Such omissions could lead to wrong conclusions in case of market segmentation, especially if some business facilities with high concentration of legal entities are omitted, and, consequently, to making bad business moves and results. A precisely coded vector map is ready for entering almost infinite data quantities.

Although a great variety of users is present within this branch of traffic i.e. service industry, the adequate division would be the one that divides all users into physical persons and legal entities, i.e. consumer market and organisational market [8].

In literature that deals with this subject matter, the general opinion is that application of some standard methods of demographic and psychographic segmentation facilitates the creation of a preliminary list of 'who buys'. Such approaches themselves do not define market rules and problems, a need for a particular service or unique advertising measures that should be implemented, but they are helpful for determining the steps to be taken for different segments, i.e. they can contribute to the implementation of segmentation project. The role of geographical criterion, in relation to other criteria that are applied in the process of segmentation, in the case of postal services may be the greatest since it leads to data where the highest concentration of actual and potential users is.

By using the option that allows the creation of thematic maps via GIS, we can quickly obtain information on the state in a certain area by this criterion. [7]

Thematic map contains all essential information related to an area. On the basis of the available data, it is possible to divide an area by a certain criterion to an adequate number of segments. Figure 2. shows the position of legal entities who demand certain service (black dots) in relation to the position of postal network units, with densities given according to the number of demanded services of this kind in an urban area.

When looking at the picture, one can instantly notice which part of the market consists of legal entities that are not the users of a certain service. Such representation could open up numerous advantages, starting from those related to the ability of identification of users whose needs related to the observed service have not been satisfied. 


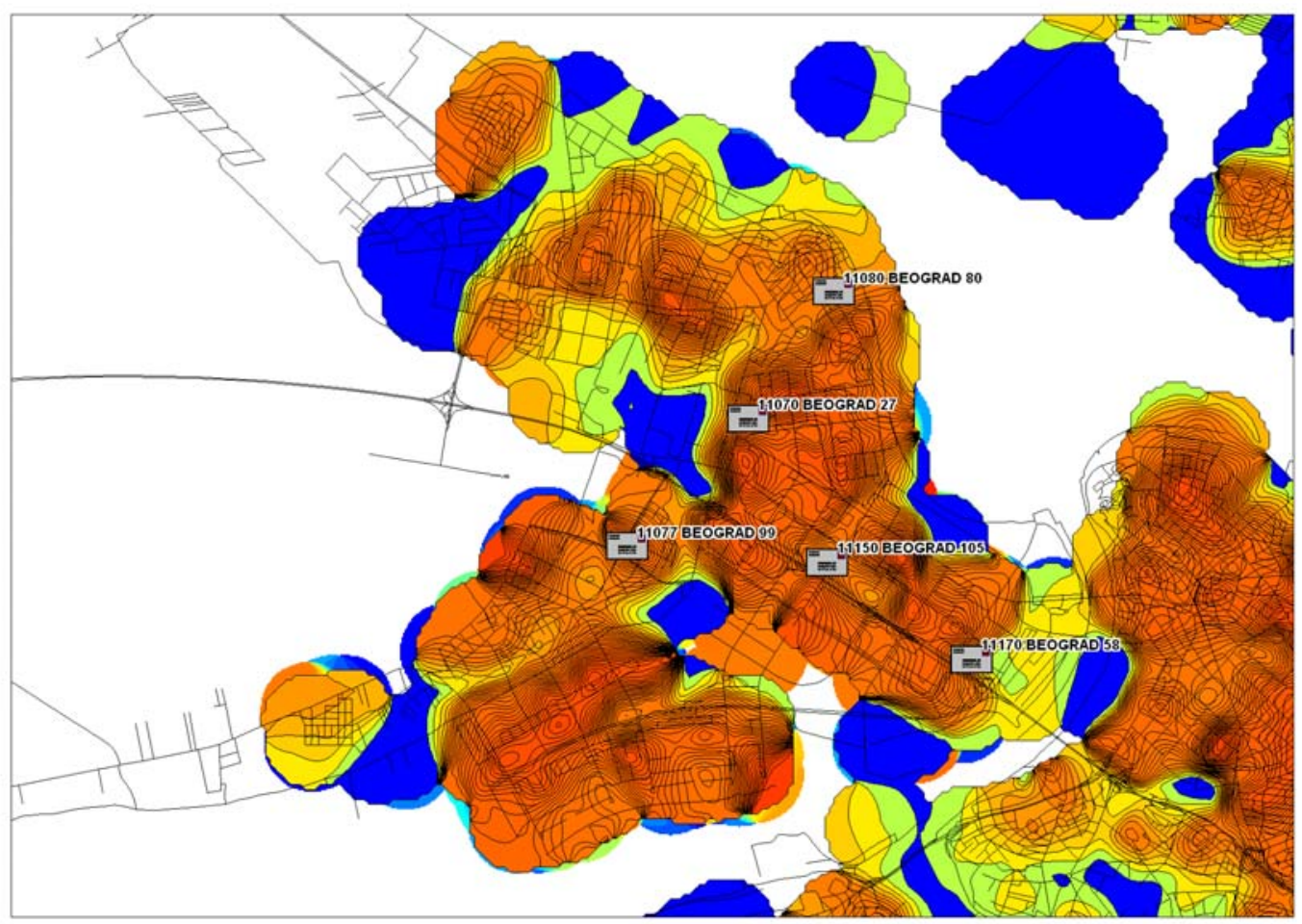

Figure 1. Population density in an urban area

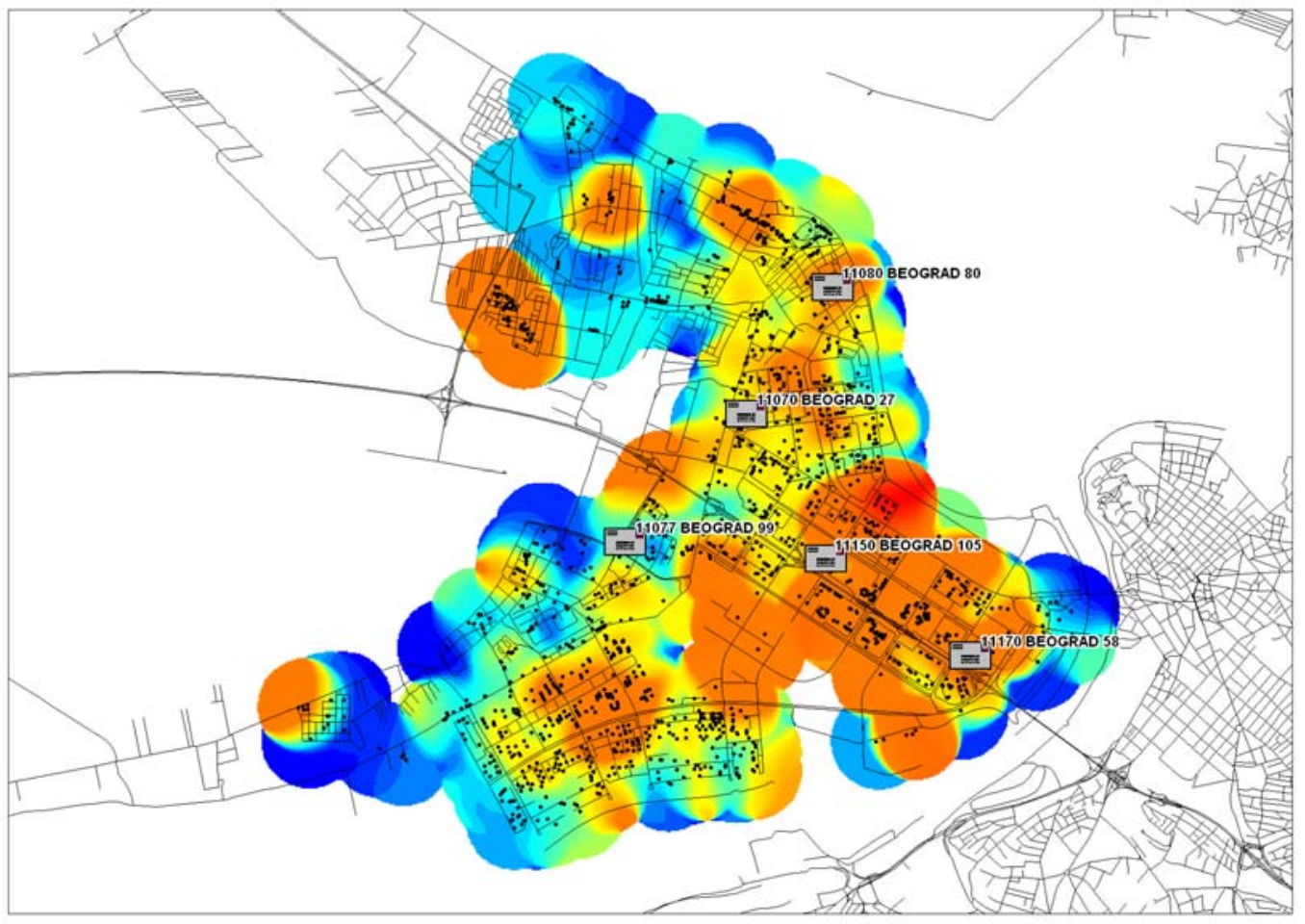

Figure 2. The position of legal entities that demand certain service in relation to the position of post offices with densities given in relation to the number of received parcels broj in a part of an urban area

When looking at the picture, one can instantly notice which part of the market consists of legal entities that are not the users of a certain service. Such representation could open up numerous advantages, starting from those related to the ability of identification of users whose needs related to the observed service have not been satisfied. 
On the basis of data from the database a decision about the size of the segment is made by connecting territories on which certain users with similar demands are located in an integral entity. That way, it would be possible to define special courier teams and means of transportation for servicing the segment of legal entities - large users.

Collecting data on all relevant parameters for an observed area, such as population, number of households, number of legal entities with names and activities, amount of parcels sorted by types, frequency of demand (daily, occasionally, rarely, only in an emergency), data that indicate whether it is individual or group demands, payment methods, time of demand, number and location of service units ....are an inexhaustible source of continuous and more effective market segmentation.

\section{Conclusion}

The idea of further running business activities in a traditional way within large postal capacities seems rather obsolete. The evident difference in burdening of particular parts of the system, as well as the need for more economic running of business activities, has brought the idea of using the advantages of computer and communicational technologies as possible solutions for a number of issues from this area.

Direct organization of business activities with users is a close future. The application of GIS is still marginal, but it is becoming more and more frequent daily. Databases are relatively simple for updating, therefore, with little technical investments and training staff to work with GIS, significant savings can be made and, at the same time, possible increase of the volume of services can be readily responded to.

Rapid creation of vector maps in all parts of the Serbian Post Office should bring along mass introduction of GIS technology in the sphere of organization of working process. The idea of its application is to enable visualization of any data with geographical context through connection with digital map, locating of the desired data on a digital map, calculating summary information for a specific area, selecting users according to specific types, analysing locations of a new postal network unit etc.

The answers to the questions such as: where are the users, what is the quality of service distribution among different user categories, in which areas has the increase in demand been registered, what part of the market is covered by executive units, what way could users be guaranteed quality services etc., give way to further studying the application of GIS technology in postal traffic.

\section{References}

[1] Development of competition in the European postal sector, MARKT/2004/03/C, Rotterdam, July 2005.

[2] MARKOVIĆ, D., GRGUROVIĆ, B.: Poštanski saobraćaj, Saobraćajni fakultet Univerziteta u Beogradu, Srbija, 2006.

[3] NEDELJKOVIĆ S., ZAGORAC DJ.: Implementation of post address code in GIS territory management, in Modern Post, Belgrade, vol. 2, 2006, pp. 68-72.

[4] DUIJNHOVEN, J. V.: Postal markets on the move, in Eurogroup Consulting magazine, no 9. 2009.

[5] Opšti plan poštanske mreže, JP PTT saobraćaja "Srbija", Beograd, 2009.

[6] MARKOVIĆ, D., GRGUROVIĆ, B., ŠTRBAC, S.: The use of spatial data for segmentation of the postal services market". Technological and Economic Development of Economy, 17: 1, 87 - 100, 2011. ISSN 2029-4913 print/ISSN 2029-4921 online 
[7] GRGUROVIĆ, B., ŠTRBAC, S.: Application of geographic information system in market segmentation of postal services, INFOTEH-JAHORINA Vol. 8, Ref. E-III-15, pp. 585-588. 2009.

[8] GRGUROVIĆ, B., ŠTRBAC, S.: Formiranje preliminarnog spiska korisnika poštanskih usluga, PosTel 2008, XXVI simpozijum o novim tehnologijama u poštanskom i telekomunikacionom saobraćaju, Saobraćajni fakultet, Beograd, Srbija, 2008, pp. 207214. 